\title{
La acción novelesca de Don Segundo Sombra
}

$\mathrm{S}^{\mathrm{E}}$ ha estudiado Don Segundo Sombra, de Ricardo Güiraldes, comparándolo con otras obras de la literatura gauchesca, ${ }^{1}$ y se ha estudiado la idealidad o realidad de los dos personajes principales del libro. ${ }^{2}$ Se han buscado en esta novela paralelos con la vida de su creador, considerándola como obra semiautobiográfica, ${ }^{3}$ y a menudo se han comentado los méritos estilísticos que contiene. Pero se ha estudiado poco la intriga o acción novelesca del libro. A veces se ha creído que la novela carece de acción, o que es deficiente en cuanto a este elemento de la arquitectura novelesca: "Aquí nos encontramos con un escritor que, sin tener talento de novelista, ha creado una obra interesantísima, una novela que peca por la pobreza de su intriga de tal modo que casi no es novela..."4

Sin embargo, Don Segundo Sombra está lejos de ser una novela sin intriga; en realidad de verdad, el libro, por lo menos para un lector no argentino, logra su finaldad artística principalmente por vía de su trama. Este aspecto de la novela, pues, es el que se estudiará aquí.

1 Véase Ramón Doll, "Segundo Sombra y el gaucho que ve el hijo del patrón", Nosotros, nov-dic., 1927, XXI, Iviii. 270-281.

2 Véase T. B. Irving, "Myth and Reality in Don Segundo Sombra", Hispania, marzo, 1957, XL, 44-48.

3 Véase Julio Molina Aguirre, "Ricardo Güiraldes", nota preliminar a Don Segundo Sombra (Madrid, 1951), págs. 11-25.

4 Arturo Torres Rioseco, Novelistas contemporáneos de América (Santiago de Chile, 1939), p. 142 , 
Si no se ha considerado detenidamente este elemento de la novela, será por dos razones: Primera, porque es cierto que el libro contiene un elemento considerable de costumbrismo pampeano. $\mathrm{Y}$ segunda, porque la índole de la acción novelesca es sutil y así quizás se ha desviado un poco la atención crítica ante un libro que trata de una sociedad tan vigorosa y pintoresca como la de la pampa argentina. De hecho, la acción consiste en el paso desde la niñez a la madurez de un muchacho algo excepcional pero, tal como nos le presenta el autor, típico. Que esto es así, lo indican varios rasgos importantes del libro: el contraste, con frecuencia observado, entre el estilo de la parte narrativa y el de los diálogos; el esquema temporal, cuidadosamente construído, de la novela; la índole del climax, etc.

Un crítico ha comparado la estructura de Don Segundo Sombra y la del Lazarillo de Tormes, y según él los caracteres, en ambas novelas, son más importantes que las aventuras; se afirma que los caracteres "han sido logrados independientemente de la trama de la obra." Aunque cuesta trabajo aceptar un criterio según el cual los personajes pueden lograrse independientemente de la trama de una novela, la comparación entre las dos obras es acertada en este sentido: en ambas novelas se encuentran a la vez un paso desde la niñez hasta la madurez y un elemento costumbrista importante. Pero es probable que en Don Segundo Sombra predomine mucho más el primero de estos elementos y en el Lazarillo el segundo.

La acción de Don Segundo Sombra consta de tres partes o períodos, de extensión distinta. La primera abarca los capítulos I-IX, la segunda los capítulos X-XXVI, y la tercera la constituye el capítulo final. Entre la primera y la segunda transcurren cinco años; entre la segunda y la tercera, tres. Si se prescinde de los breves resúmenes dados en los capítulos I y XXVII, la narración sólo abarca unos cuantos meses de la vida del protagonista. (Así, la afirmación de E. Anderson Imbert, según la cual Don Segundo Sombra "es la novela de unos tres años de aprendizaje gaucho en la vida de un huér-

๑. Ibid. 
fano," parece inexacta).$^{6} \mathrm{El}$ protagonista tiene catorce años al comenzar la acción y veintitantos al final del libro. Ya que a Güiraldes le es característico el empleo de lo simbólico, no extraña que el protagonista carezca de nombre y apellido hasta haber conseguido la madurez; que sea sólo cuando puede decir don Leandro Galván "ya... te has hecho hombre," que se revelen su nombre y su identidad social mediante la muerte y testamento del padre.

La primera parte se inicia el día en que conoce el muchacho a don Segundo Sombra. El capítulo I da un resumen sucinto de las impresiones que conserva el protagonista de su vida anterior - las visitas que le hacía su protector de identidad enigmática, don Fabio Cáceres, la separación de madre e hijo, la llegada de éste al pueblo para asistir al colegio bajo la inspección nada amable de sus presuntas tías- y de su impaciencia con la vida aburrida del pueblo. Se echa de ver en seguida el contraste entre el habla gaucha del diálogo y la prosa exacta, densa, culta de la narración. En el segundo capítulo se produce el encuentro con don Segundo; reacciona el muchacho de una manera inmediata e intensa: "Me pareció haber visto un fantasma, una sombra, algo que pasa y es más una idea que un ser; algo que me atraía con la fuerza de un remanso, cuya hondura sorbe la corriente del río... Entreveía una vida nueva hecha de movimiento y espacio."7 Como conviene, don Segundo es una figura de misterio: "Era el 'tapao,' el misterio, el hombre de pocas palabras que inspira en la pampa una admiración interrogante."8 Lo único que se nos dice aquí de su pasado es que viene de San Pedro. La forma narrativa de la novela contribuye eficazmente a establecer el carácter de don Segundo: le vemos siempre por los ojos del protagonista, para el cual es la personificación heroica de aquella madurez que por instinto busca. Casi inmediatamente don Segundo, que está buscando nueva colocación de domador, y el protagonista se encuentran

- Enrique Anderson Imbert, Historia de la literatura bispanoamoricana (México, 1954), pág. 284.

7 Ricardo Güiraldes, Don Segundo Sombra (Buenos Aires, 1950), págs. 17-18. (Se cita siempre en este trabajo la décima edición publicada por Losada).

8 Ibid., pág. 21. 
unidos en una relación más firme y sólida que la de una amistad ordinaria: el muchacho ayuda a salvarle la vida a don Segundo avisándole a tiempo del ataque que le va a hacer el borracho tape Burgos. En este episodio, manifiesta don Segundo la destreza física y la grandeza moral que son aspectos principales de su carácter.

Sintiéndose unido a don Segundo, sale el muchacho de casa para ir primero a la estancia de Galván; allí consigue que le contraten también a él mientras don Segundo trabaja de domador. A esta entrada en la nueva vida sigue el primer arreo. Don Segundo le anima para que trate de formar parte del grupo que va a participar en el arreo; con la brevedad que le es característica, dice don Segundo: "Cuando yo tenía tu edá, le hacía el gusto al cuerpo sin pedir licencia a naides."9 Güiraldes, sirviéndose como siempre de su protagonista para llevar el hilo de la narración, refiere, de manera concisa, pero sin omitir nada de importancia, los preparativos del arreo y las primeras jornadas del mismo. En la primera parada, se indica el progreso ya realizado en este viaje de sentido doble mediante la admiración que siente por el héroe un muchacho dos años más joven: "Su ingenua prueba de curiosidad admirativa era mi boleta de resero." 10 Al término del primer día de arreo, siente el protagonista un rebencazo "casi insensible" y oye que le dicen: "iHacéte duro, muchacho! Y creía haber reconocido la voz de don Segundo."11 $\mathrm{Y}$ finaliza la primera parte, mientras continúa el arreo, con las palabras: "Caminar, caminar, caminar."12 Terminación magistral y a la vez transición a la segunda parte, en la cual se verá la adquisición del dominio y de la madurez.

La estructura de esta segunda parte es más compleja. Consiste en una serie de episodios que, en su totalidad, constituyen un panorama de las actividades y experiencias características de la vida de un gaucho. $\mathrm{Y}$ a la vez cada episodio ayuda a comprender la formación de la personalidad adulta

9 Ibid., pág. 37.

30 Ibid., pág. 53.

11. Ibid., pág. 57 .

12 Ibid., pág. 62. 
del protagonista. Estas aventuras están narradas todas desde el punto de vista de un hombre maduro. Se sitúan en un presente vívido, y a la vez se interpretan reflexivamente: descripciones de una riña de gallos, una carrera de caballos, rodeos, una feria campestre, el desarrollo de amistades masculinas, un amorío, un encuentro con lo sobrenatural. "Cinco años de esos hacen de un chico un gaucho, cuando se ha tenido la suerte de vivirlos al lado de un hombre como el que yo llamaba mi padrino."13 Y aunque don Segundo, la personificación del ideal, entra en escena con igual frecuencia que en la primera parte de la novela, cambia ahora la relación entre ambos. No necesita el muchacho de la ayuda de su padrino ni en el rodeo ni en la lucha con el toro, ni, desde luego, en la pelea con Numa. Se dilata el mundo del joven: amistades con Patrocinio y Antenor, amores con Paula. El hombre mayor comenta e interpreta lo que acontece; y, cuando demuestra el muchacho su pericia de domador, es a él y no a don Segundo a quien el patrón quiere contratar. He aquí una oportunidad para emanciparse, pero no la acepta el joven por la lealtad que siente para con don Segundo, quien ahora comienza a retirarse hacia el fondo del cuadro. Le queda al padrino, sin embargo, la importante tarea de ayudar al muchacho a que venza una dificultad final, a que entre en la última fase de su desarrollo. La índole de ésta ya se había indicado durante un curioso momento de alucinación que experimentó el muchacho al reponerse de las lesiones sufridas en el encuentro con el toro bravo que le había corneado los caballos. En aquel momento (capítulo XVIII), había soñado estar de nuevo en la estancia de Galván, donde oía al estanciero decirle: "-Ya has corrido mundo y te has hecho hombre, mejor que hombre, gaucho... Allí te espera tu estancia y, cuando me necesites, estaré cerca tuyo-... Me habían sucedido cosas extraordinarias y sentía casi como si fuera otro... otro que había ganado algo grande e indefinido, pero que tenía asimismo una impresión de muerte."14 Se confirma este presentimiento en el capítulo XXV al llegar Pedro Barrales con una

13 Ibid., pág. 63.

14 Ibid., pág. 125. 
carta de Galván informándole al muchacho del fallecimiento de su padre, don Fabio Cáceres, cuyo nombre y propiedad hereda. Ahora, por última vez, se impone tranquilamente don Segundo, quien, al consentir en acompañar al joven, consigue que éste venza su repugnancia y abandone la vida de resero. Éste, el momento culminante de la acción, es el episodio de la trama más difícil de explicar según las normas de la probabilidad. Lo de la herencia, caída de las nubes, tiene carácter artificioso: ¿por qué sólo ahora se clarifican el misterio del nacimiento del protagonista y las circunstancias de su vida? Sin duda cabe suponer que un hombre rico haya querido, mientras vivía, mantener oculto el que tenía un hijo ilegítimo. Sin embargo, el episodio forma parte de la lógica de la novela. Desde el comienzo, sabemos que el narrador dejó de ser gaucho, y el desarrollo de la trama exige que por fin se separe de Sombra y de su modo de vivir. El libro es la narración de una experiencia recordada con nostalgia, algo que, aunque vívidamente recreado, se sabe que ha acabado. Terminado, no sólo en el sentido de que los acontecimientos se sitúan en el pasado, sino también en el de que el punto de vista adoptado sería imposible para un gaucho de los que están retratados en el libro, hasta para el protagonista, si no hubiera abandonado aquel género de vida. Es en este punto de vista donde se encuentra la clave de la novela, lo que da al libro su sabor y significación. Es la historia del paso de la niñez o de la adolescencia a la madurez, recordada, refundida por la persona adulta, bien instruída, culta, quien lleva en sí la historia "sacramente, como la custodia lleva la hostia," como dice el autor, en la dedicatoria de su novela, del gaucho que en sí lleva. $Y$, desde luego, he aquí la explicación de por qué posee esta novela un atractivo mayor y más universal que el de una novela costumbrista. Es el contraste sutil entre los acontecimientos narrados y la manera en que se narran -contraste que se da por todo el libro- lo que ensalza el significado de la acción de la obra; es tanto, o más, por medio de la resolución de la tensión inherente en este contraste; como por la mera narración de los últimos episodios de la acción, por lo que alcanza la novela su forma completa y acabada, 
Es esta novela una obra rica y compleja. El que se haya hablado aquí principalmente de la estructura de la acción y de su significado no quiere decir que el elemento costumbrista del libro carezca de importancia. Más bien, lo costumbrista ha de verse como una parte del contenido de la experiencia artísticamente elaborada. Sirvan de ejemplo los dos cuentos de don Segundo (capítulos XII y XXI), omitidos en una versión escolar de la novela porque, según los editores, no tienen nada que ver con la trama.15 De estos cuentos dice el protagonista: "Sus relatos introdujeron un cambio radical en $\mathrm{mi}$ vida... Mi fantasía empezó así a trabajar, animada por una fuerza nueva, y mi pensamiento mezcló una alegría a las vastas meditaciones nacidas de la pampa."16 No se descuidó Güiraldes al escribir este libro. La intriga la constituye una de las acciones más complejas que se puede escoger, y ha selec. cionado el autor con juicio los episodios indispensables. En efecto, la novela en su totalidad está organizada de una manera extraordinariamente compacta y económica. La manera narrativa, el estilo, la intriga y los caracteres están combinados en una estructura novelesca singularmente adecuada $y$ bien adaptada al propósito artístico del autor.

Donald Fabian, Universidad de Chicago.

15 Ed. Ethel W. Plimpton and María T. Fernández, Don Segundo Sombra (New York, 1945), p. iii.

16 Don Segundo Somóna, pág. 65, 
